\title{
Economic and Psychosocial Impacts of Health Evacuations Abroad for Coronary Angioplasty in Togolese Patients
}

\author{
Mouhaman-Inouwa Kpelafia1*, Soulemane Pessinaba1, Abdou Razak Moukaila², \\ Marodégueba Barma', Nkenon Watani N'Da1, Yawo Dodzi Molba Atti', \\ Ekpé Togbossi', Komlavi Yayehd', Findibe Damorou1 \\ ${ }^{1}$ Department of Cardiology, CHU Campus, University of Lomé, Lomé, Togo \\ ${ }^{2}$ Department of Internal Medicine, University of Lomé, Lomé, Togo \\ Email: *kpelafiamohamed@yahho.fr
}

How to cite this paper: Kpelafia, M.-I., Pessinaba, S., Moukaila, A.R., Barma, M., N’Da, N.W., Atti, Y.D.M., Togbossi, E., Yayehd, K. and Damorou, F. (2021) Economic and Psychosocial Impacts of Health Evacuations Abroad for Coronary Angioplasty in Togolese Patients. World Journal of Cardiovascular Diseases, 11, 583-592.

https://doi.org/10.4236/wjcd.2021.1112055

Received: November 3, 2021

Accepted: December 18, 2021

Published: December 21, 2021

Copyright $\odot 2021$ by author(s) and Scientific Research Publishing Inc. This work is licensed under the Creative Commons Attribution International License (CC BY 4.0).

http://creativecommons.org/licenses/by/4.0/

\begin{abstract}
Introduction: Coronary artery disease is the leading cause of premature death worldwide. The management of its severe form requires angioplasty, not yet available a year ago in Togo, which motivated the evacuation of Togolese patients with this disease. Objectives: To evaluate the cost of angioplasty and the economic and psychosocial impacts in evacuated Togolese patients. Methodology: This was a three-year descriptive and prospective study (January 2015 to December 2018) that included all Togolese patients evacuated for coronary angiography from 4 health facilities in the city of Lomé. Results: The mean age was $56.8 \pm 11$ years. There was a male predominance with a sex ratio of 2.63. The main countries of evacuation were France (50\%), Tunisia (25\%) and Ivory Coast (20\%). The main indications of coronary angiography were myocardial infarction in $47.5 \%$, NSTEMI (22.5\%) and ischemic heart disease (15\%). Fifty-five percent of the patients had monotroncular involvement. Angioplasty was performed in 16 patients, 3 patients had bypass surgery and only one patient had medical treatment. Sixty percent of patients received an active stent and $20 \%$ a bare stent. The total cost of the 40 evacuations was four hundred and fifty one thousand four hundred and nineteen US dollars (US\$451,419). The average cost per evacuation was eleven thousand two hundred and eighty-six US dollars (US\$11,286), or 182 times the Togolese minimum wage. At the announcement of the disease and evacuation, $40 \%$ had been afraid and 35\% had accepted their illness. Fifty-five percent perceived evacuation as a healthy outcome. In $25 \%$ of cases the coronary angiography was simple and $20 \%$ found it painful. After the coronary angiography $40 \%$ had regained hope of recovery, $37.5 \%$ had accepted their result
\end{abstract}


and $37.5 \%$ were happy with the outcome. Conclusion: Coronary artery disease is a serious pathology in terms of cardiovascular morbidity and mortality, especially its severe form, which is myocardial infarction, the treatment of which requires angioplasty. This comes back during an evacuation that is too expensive for the average Togolese; only its implementation in our country remains the solution to fight against its often fatal complications as well as the flight of capital and the stress of patients and their families.

\section{Keywords}

Evacuation, Cost, Angioplasty, Economic Impact, ACS

\section{Introduction}

Cardiovascular diseases are a public health problem because of their very high morbidity and mortality worldwide. Mainly coronary artery disease is the leading cause of premature death today [1].

In 2015, an estimated 17.7 million deaths were attributable to cardiovascular disease, representing $31 \%$ of total global mortality. Of these deaths, an estimated 7.4 million are due to coronary artery disease and 6.7 million to cerebrovascular accident (stroke) [1].

More than three quarters of cardiovascular disease deaths occur in low- and middle-income countries [1].

In Togo in 2010, coronary artery disease represented $7.3 \%$ of cardiovascular diseases with a high case fatality rate of $27.9 \%$ [2]. People with coronary artery disease require early diagnosis for adequate care. It should be noted that coronary angiography with angioplasty, a technique for rapid and effective myocardial revascularization, does not yet exist in Togo.

Only patients with sufficient financial resources are able to afford the costs of angioplasty treatment for myocardial infarction in foreign countries, either during an emergency medical evacuation or after stabilization of their clinical condition.

This situation not only constitutes a flight of capital abroad for the country, but also a state of intense stress for the patients and their families.

The objective of this work was to evaluate the economic and psychosocial impacts of evacuations abroad for angioplasty of Togolese patients in order to bring the Togolese government to relieve the population by setting up a catheterization room.

\section{Methodology}

We conducted a three-year prospective study from January 2015 to December 2018, using data from patient records in four health facilities in the city of Lomé offering cardiology care.

Included in our study were all patients, regardless of age or gender, who were 
evacuated to a foreign country during the study period from the four health facilities for coronary angioplasty. For data collection, cardiologists from each facility were contacted by phone for an appointment. An explanation of the topic and the survey form was given and then once their agreement was obtained, a list of patients with their contacts was drawn up by each cardiologist. Patients were contacted if needed. We then proceeded to fill in the survey forms. We recorded data that we finally analyzed. The parameters studied were:

- Socio-demographic data: age (in years), gender (male or female), occupation and insured or uninsured status.

- Anthropometric parameters: weight $(\mathrm{kg})$, height $(\mathrm{cm})$, body mass index $\left(\mathrm{kg} / \mathrm{m}^{2}\right)$, waist circumference $(\mathrm{cm})$ and systolic $(\mathrm{SBP})$ and diastolic (DBP) blood pressure.

- Indication of coronary angiography, country of patient evacuation, topography of lesions, type of treatment: angioplasty, type of stent and bypass surgery; cost of coronary angiography, cost of travel, cost of angioplasty and total cost of evacuations, taking into account the actual costs that have been charged to patients.

- The psychosocial impact: impact on the patient: his reaction to the announcement of the disease and evacuation, his perception of the disease, his perception of evacuation, the experience of the disease, the experience of the coronary angiography and his reaction to the announcement of the coronary angiography result. As well as the impact on family and professional environment.

Data were entered and analyzed using Epi Data 3.1 software. The statistical analysis was carried out using Epi info 7 software. The categorical variables, presented as numbers and percentages, were compared using the $\mathrm{Chi}^{2}$ test or Fisher's exact test. Continuous variables, presented as means and standard deviations, were compared using the Kruskall-Wallis test. The significance level was obtained for a value of $\mathrm{p}<0.05$.

\section{Results}

During our study, 40 Togolese patients were evacuated for coronary angiography including 29 men and 11 women, i.e. a sex ratio of 2.63 in favor of men. The mean age was $56.8 \pm 11$ years with extremes of 33 and 89 years. The age group between 50 and 59 years $(47.5 \%)$ was the most represented. Thirty-two point five percent were insured and 52.5\% uninsured. Employees in the private sector were the most represented (32.5\%). The evacuation countries were France (50\%), Tunisia (25\%), Ivory Coast (20\%), Morocco (2.5\%) and Senegal (2.5\%).

None of our patients had received an emergency evacuation. All of our patients had received medical treatment for ischemia prior to coronary angiography. The main indications for coronary angiography were myocardial infarction in $47.5 \%$, NSTEMI (22.5\%) and ischemic heart disease (15\%). On coronary angiography $50 \%$ was normal and $50 \%$ had at least one lesion. Fifty-five percent of 
the patients had monotroncular, 25\% bitroncular and 20\% tritroncular lesions. Eighty percent of patients with lesions had undergone angioplasty, $15 \%$ had undergone coronary artery bypass grafting and one had undergone medical treatment. Of the patients who underwent stent angioplasty, $60 \%$ of patients received an active stent and $20 \%$ a bare stent (Table 1 ).

The total cost of the 40 evacuations amounted to 255,481,242 CFA francs, or US\$451,419. The average cost per evacuation amounting to 6,387,031 CFA francs (US\$11,286). This cost is equivalent to one hundred and eighty-two times the Togolese minimum wage in 2019. The simulated cost of 100 and 500 evacuated patients amounts to $638,703,105 \mathrm{~F}$ CFA (US\$1,128,547) and 3,193,515,525 F CFA (US\$5,642,737) respectively (Table 2).

Table 1. General characteristics of the population and indications for coronary angiography.

\begin{tabular}{lcc}
\hline \multicolumn{1}{c}{ Parameters } & Total & Percentage \\
\hline Number of patients & 40 & $100 \%$ \\
Average Age & $56.8 \pm 11$ & - \\
Sex ratio & 2.63 & - \\
Insured & 13 & $32.5 \%$ \\
Uninsured & 27 & $67.5 \%$ \\
Hypertension & 26 & $65 \%$ \\
Diabetes & 10 & $25 \%$ \\
Dyslipidemia & 11 & $27.5 \%$ \\
Obesity & 10 & $25 \%$ \\
Overweight & 19 & $47.5 \%$ \\
HIV & 3 & $7.5 \%$ \\
Indications for coronary angiography & & \\
ACS ST+ & 19 & $47.5 \%$ \\
ACS ST- & 9 & $22.5 \%$ \\
Ischemic heart disease & 6 & $15 \%$ \\
DCM & 3 & $7.5 \%$ \\
\hline
\end{tabular}

Table 2. Evaluation of the various costs.

\begin{tabular}{lcc}
\hline \multicolumn{1}{c}{ Costs } & Amounts in FCFA & Amounts in dollars \\
\hline Total cost of the trip & $23,103,100$ & 40,771 \\
Total cost Coronary angiography & $85,786,942$ & 151,385 \\
Total cost Angioplasty & $87,641,200$ & 154,656 \\
Total cost of coronary bypass surgery & $58,950,000$ & 104,177 \\
Total cost of the 40 evacuations & $255,481,242$ & 451,419 \\
Average cost of an evacuation & $6,387,031$ & 11,286 \\
Simulated cost of 100 evacuations & $638,703,105$ & $1,128,335$ \\
Simulated cost of 500 evacuations & $3,193,515,525$ & $5,641,612$ \\
\hline
\end{tabular}


When the disease and evacuation were announced, $40 \%$ were afraid, 35\% accepted and $17.5 \%$ were indifferent. Forty percent of the patients thought their illness was natural, 7.5\% thought it was mystical. Based on their experience of the disease, $37.5 \%$ were anxious, $25 \%$ depressed and $25 \%$ still had a hope for a cure. Fifty-five percent of the patients perceived evacuation as a healthy outcome while $7.5 \%$ saw it as the announcement of their imminent death. Sixty-two point five percent had viewed the evacuation as a hope of defeating their illness while $20 \%$ were angry with the country's authorities. In $25 \%$ of cases, the coronary angiography was simple and $20 \%$ found it painful. After the coronary angiography $40 \%$ had found hope for recovery, 37.5\% had accepted their result and $37.5 \%$ were happy with the result. Seventeen point five percent of families feared the outcome while $7.5 \%$ feared the expenses (Table 3 ).

\section{Discussion}

Interventional cardiology requires the training as an interventional cardiologist and technical platform. Until July 2019, there was no catheterization room on the Togolese territory. Only patients with substantial financial means could seek treatment abroad either through their own funds or through the private insurance that their function conferred.

In our study, the mean age of our patients was $56.8 \pm 11$ years with extremes between 33 and 89 years. This condition affects the active and still young social layer in our country.

Thirty-two point five percent were insured, of which $22.5 \%$ in private insurances and $10 \%$ with the National Institute of Health Insurance (INAM). $67.5 \%$ of the patients had fully covered the costs of their evacuation.

In Togo, the INAM which insures public sector employees does not cover health care abroad according to article 4 of the decree $\mathrm{N}^{\circ} 2011-035 / \mathrm{PR}$ on the partnership regime between the INAM and health facilities [3]. This situation limits medical evacuations of public sector workers, as they are unable to pay for their care themselves.

In the work of N'GUETTA et al. in Abidjan, more than three quarters of patients had paid the full costs of their angioplasty, unlike in developed countries where health coverage allows greater accessibility. This medico-economic aspect is a hindrance to angioplasty activity in sub-Saharan Africa [4].

The total cost of treating the 40 patients amounted to 255,481,242 FCFA (US\$451,419), or an average cost per evacuation of 6,387,031 FCFA (US\$11,286), which is 182 times the minimum wage in Togo.

By simulation, if 500 patients were evacuated abroad, this would cost Togo approximately 3.2 billion FCFA (US\$5,642,737). This sum could pay for the construction of both an interventional cardiology room and a latest generation cardiac surgery unit [5].

In Senegal in 2015, according to $\mathrm{Ba}$ et al. [6], the average cost of evacuating a patient abroad was 5 million FCFA. The 500 evacuated patients amounted to 2.5 
Table 3. Psychosocial factors associated with evacuation.

\section{Psychosocial parameters}

Reaction to announcement of illness and evacuation

Fear

Acceptance

Indifference

Collapse

Refusal of acceptance

\section{Perception of the disease}

Natural disease

External aggression

Disruption of the course of existence

Divine punishment

Living with the disease

Anxiety
Depression
Hope
Disappointment
Despair

\section{Perception of evacuation}

Healthy outcome

Announces the coming death

Departure without return

\section{Evacuation experience}

Hope

Anger against the authorities

Anger against caregivers

Fear

Impotence

Coronary angiography experience

Simple

Healthy

Painful

I did not expect that

That's all

Reaction to the announcement of the result

Hope for recovery

Joy

Acceptance

Relief

Shock/collapse

Family's evacuation experience

Fear of outcome

Fear of expenses

Painful separation
Total (\%)

$16(40 \%)$

$14(35 \%)$

$7(17.5 \%)$

$4(10 \%)$

$3(7.5 \%)$

$16(40 \%)$

$3(7.5 \%)$

$3(7.5 \%)$

$1(2.5 \%)$

15 (37.5\%)

$10(25 \%)$

$10(25 \%)$

$6(15 \%)$

5 (12.5\%)

22 (55\%)

$3(7.5 \%)$

2 (5\%)

$25(62.5 \%)$

$8(20 \%)$

$4(10 \%)$

$6(15 \%)$

$2(5 \%)$

$10(25 \%)$

4 (10\%)

8 (20\%)

$4(10 \%)$

$2(5 \%)$

$16(40 \%)$

$15(37.5 \%)$

$15(37.5 \%)$

$12(30 \%)$

$3(7.5 \%)$

$3(7.5 \%)$ 
billion FCFA. Whereas the cost of consumables to care for 500 patients in Dakar was 261 million FCFA, a substantial saving of more than 2 billion FCFA for the country.

Consequently, the outflow of foreign currency from Togo during the evacuations would weaken the national economy. It would be beneficial to improve the technical facilities of our hospitals and train specialized cardiologists in order to put an end to these costly evacuations, which only represent the visible part of the Iceberg. It should be noted that the majority of our poor patients, for lack of means, most often succumb to their disease simply because our hospitals do not have the technical means to save them, in front of sad and helpless caregivers.

On the psycho-social level, at the announcement of their illness and evacuation, $40 \%$ of our patients had been afraid, $35 \%$ had accepted their illness, $17.5 \%$ were indifferent, $10 \%$ had collapsed (dumbfounded) and $7.5 \%$ refused to accept the diagnosis (denial of the diagnosis).

Communicating a diagnosis of serious illness, announcing a recurrence of cancer, announcing the decision to stop chemotherapy, explaining the justification for a transfer to a palliative care unit: the announcement of bad news refers to various clinical situations that are always very difficult for the patient. Thus, despite the implementation of an announcement device, despite the doctor's goodwill and despite the precautions that he or she can take and surround his patient with in order to lessen the shock, this step can still go wrong [7].

Ruszniewsky describes the announcement as still a shock. Even prepared, anticipated, well delivered, softened to the maximum, spoken with tact and empathy, the announcement always erupts. The words of the announcement psychically kill the one who receives them and worry in advance the one who knows he will have to say them [8].

Dusabe A. et al. had found the following reactions at the announcement in patients suffering from liver cancer: fear (100\%) denial (82.6\%) and astonishment (81.4\%), anxiety (75.6\%) and crying (61.6\%) [9].

The figures found in our study are low compared to those found by Dusabe et al.; this can be explained by the hope of recovery and survival of cardiac patients compared to patients with liver cancer who have a much poorer prognosis.

In any case, the announcement of an illness is usually a paradoxical dialogue: the patient asks the doctor for the truth about his medical results; while wishing to receive only good news. While the doctor asks the patient to integrate a traumatic diagnosis without intellectual difficulty or emotional demonstration [7]. This announcement provokes a trauma for which the patient will set up a defense mechanism. To this is added a second announcement, that of evacuation without which the patient's outcome would be pejorative. This situation would worsen the first trauma suffered.

Regarding the experience of the evacuation, $62.5 \%$ had found hope of recovery through it, while $30 \%$ had felt anger against the authorities and caregivers at the constraints of the evacuation. Indeed, evacuating a patient is not easy. This mobilizes not only financial resources but also a substantial human resource. For 
a successful evacuation, excellent coordination between the different actors is needed, and therefore regulation is a crucial point; these actors are: the regulating doctor (doctor from an assistance company, or a doctor from the emergency medical assistance service), the applicant (doctor or surgeon from the field hospital); conveyors, and in particular air transport; and the recipient (concerned department of the destination hospital). The problem of medical regulation is therefore twofold: to make a quick decision, since it is an emergency; but take an appropriate decision because once the plane has left, with the personnel and equipment, it is too late to change the team; on the other hand, the regulating doctor can change the destination if the patient's condition requires it [10]. In all, it is a state of stress for the patient but also for the other different actors.

Patrice Jammet reported: "I had a difficult experience with my 9-year-old daughter's Evasan, especially the difficulties before leaving and once there in Paris (language, lack of financial means...). Previously, some patients were sent to Paris without preparation".

"We do psychological counseling. We bring this human dimension to Evasan. We reassure the families who are not living well with the departure of the patient. You have to receive them, prepare them (information, advice on the choice of the accompanist...), play down the Evasan which is frightening, synonymous with death for many... There is always this question: 'Will I come back?' alive or in a box?" [11]. Hence the importance of a preliminary preparation of each patient and his family before his medical evacuation. This will significantly reduce the fear and stress during evacuations.

As for the perception of their illness after the announcement, forty percent of the patients had thought that their illness was natural, $7.5 \%$ thought it was an external aggression, $7.5 \%$ an upheaval in their life and $2.5 \%$ that it was a divine punishment.

Bagny A. et al. in patients hospitalized for hematemesis, had found that $47 \%$ perceived their illness as temporary, $84 \%$ as a serious illness, $40 \%$ as a divine curse and $58 \%$ as a spell (mystic) [12].

These different results can be explained by the fact that the two studies were done on different diseases.

Regarding the experience of the disease, $37.5 \%$ of patients were anxious, $25 \%$ still had hope for recovery, and $25 \%$ were depressed. Fifteen percent were disappointed and $12.5 \%$ desperate.

While in the work of Bagny et al. in patients hospitalized for hematemesis, $83 \%$ were anxious, $53 \%$ had crying spells, $61 \%$ a feeling of imminent death and $38 \%$ a feeling of guilt [12].

All these psychosocial factors further weaken patients as well as their families and friends when faced with a curable disease but unable to seek treatment due to lack of technical facilities in the country and a lack of financial means to pay for evacuation in most cases. This fact shows once again the fragility of the Togolese healthcare system. 


\section{Conclusions}

Coronary artery disease is a serious pathology in terms of cardiovascular morbidity and mortality. The full management of its severe form, which is the acute coronary syndrome with permanent ST delay, requires angioplasty.

Our study is a first in Togo. It calls on the one hand to Togolese cardiologists to specialize in interventional cardiology which is of paramount importance to improve the time and prognosis of their patients' care, and on the other hand the health, economic and finances authorities to build a catheterization room in Togo. For this would relieve Togolese patients who spend large sums of money abroad, responsible for capital flight that weakens our national economy: building a catheterization room for Togo is a matter of national dignity.

\section{Conflicts of Interest}

The authors declare no conflicts of interest regarding the publication of this paper.

\section{References}

[1] Organisation Mondiale de la Santé (2017) Maladies Cardiovasculaires, Principaux Faits.

http://www.who.int/fr/news-room/fact-sheets/detail/cardiovascular-diseases-(cvds)

[2] Damorou, F., Baragou, S., Pio, M., et al. (2014) Morbidité et mortalité hospitalière des maladies cardiovasculaires en milieu tropical: Exemple d'un centre hospitalier à Lomé (Togo). Pan African Medical Journal, 17, 62.

https://doi.org/10.11604/pamj.2014.17.62.2237

[3] https://inamtogo.com/accessibilite-a-des-soins-de-qualite/

[4] N'Guetta, R., Ekou, A. and Yao, H. (2018) Angioplastie coronaire dans les syndromes coronariens aigus en Côte d'Ivoire: Difficultés et résultats. Annales de Cardiologie et d Angéiologie, 67, 244-249. https://doi.org/10.1016/j.ancard.2018.04.004

[5] Direction du système d'information et de la communication (2013) Renouvellement de la salle d'angio-coronarographie du Centre hospitalier de Troyes. Dossier de presse, Troyes. https://studylibfr.com/doc/4925552/dossier-de-presse

[6] Source APS (2015) Hôpital Le Dantec: Le nouveau matériel peut mettre fin aux évacuations à l'étranger. http://www.servicepublic.gouv.sn/index.php/demarche_administrative/actu/1/1457

[7] Ruszniewski, M. and Bouleuc, C. (2012) L'annonce d'une mauvaise nouvelle médicale épreuve pour le malade, défi pour le médecin. Laennec, 60, 24-34. https://doi.org/10.3917/lae.122.0024

[8] Ruszniewsky, M. and Rabier, G. (2015) L'annonce, Dire la maladie grave. Hors Collection, Dunod, Parrution.

[9] Dusabe, A., Bouglouga, O., Barma, M., et al. (2018) Aspects psychopathologiques liés à l'annonce du cancer du foie: Cas des patients suivis dans le Service d'Hépato Gastro Entérologie du CHU-Campus de Lomé. Psy Cause, 76, 45-48.

[10] Pats, B., Debien, B. and Borne, M. (2007) Les evasan stratégiques: Principes d'organisation et de régulation. Réanoxyo, 21, 8-11.

[11] Fédération "A tauturu ia na": Une mission, le soutien psychologique aux évasanés. http://www.manureva.net/images/pdf/Dossier112.pdf 
[12] Bagny, A., Bouglouga, O., Djibril, M., et al. (2010) Aspects psychopathologiques au cours des hématémèses au Togo: Représentation et vécu chez le patient. Journal Africain d Hépato-Gastroentérologie, 4, 216-219.

https://doi.org/10.1007/s12157-010-0207-5 